\title{
The Measurement of Thiol Reactivity in Cigarette Smoke*
}

\author{
by H. Gaisch and U. Nyffeler \\ Philip Morris Europe, Research Laboratory, Neuchâtel, Switzerland
}

\section{INTRODUCTION}

The cigarette is an industrial product which is based largely on a material provided by nature: tobacco. Cigarettes are consumed in a unique way: one end is lighted and the products of partial combustion and pyrolysis, mixed with air, are pulled through the cigarette to be brought into brief contact with the tissues in the mouth, larynx, trachea and lungs. During this brief contact subtle chemical interactions with the biologic systems occur that result in the formulation of the subjective impression of taste, the initiation of a complex physiologic response $(1-6)$, and, to a certain extent, other local tissue reactions ( 7 ).

Chemical investigations of cigarette smoke are traditionally aimed at providing a quantitative evaluation of smoke under standardized conditions. A typical example of this is the Coresta standard method which defines the determination of dry particulate matter (8).

However, it is clear that the condensed particulate matter is quite different in chemical terms to the original particulate matter suspended in the aerosol called cigarette smoke - but this is to no disadvantage. On the contrary, proceeding in this manner ensures good reproducibility and accuracy.

In addition to the usual chemical parameters of smoke such as particulate matter, nicotine, etc...., a measurement was sought that would characterize the passing interactions that occur on the moist tissue surfaces of the smoker, and that might be indicative of his response to smoke quality in more subjective terms.

Experiments and reviewing the pertinent literature led us to choose the thiol group as reagent for interaction and for capturing the quasi instantaneous reactivity of passing fresh smoke (7). Thiol groups react with aldehydes, unsaturated carbonyls, nitric oxide, and other compounds which are relatively unstable and could therefore easily be lost in lengthy chemical analyses (9).

A method which uses unsophisticated equipment and takes only little time was developed some three years ago in this laboratory. As it provided us with useful results it was thought to be possibly of interest to others.

Testa and Joigny reported as early as in 1972 on a method for the determination of $\alpha, \beta$-unsaturated compounds of the gas phase of smoke using a thiol reagent.

\footnotetext{
- Presented at the meeting of the Coresta Smoke Study Group, held in Copenhagen, Denmark, in September 1975.
}

It differs from our method in that it traps the gas phase prior to the thiol reaction in an aqueous solution on a chromatographic column. Certain defined reaction products are subsequently determined by gas chromatography (10). Although the principle of the method is similar, our method determines a wider range of components of fresh, un-aged smoke.

\section{PRINCIPLE OF THE METHOD}

The naturally occurring amino acid cysteine, in its hydrochloride (salt) form, is water-soluble. It reacts only very slowly with the oxygen of the air but its free thiol group interacts rapidly with smoke when an aqueous solution of cysteine is brought into contact with smoke.

In order to simulate human cigarette smoking, a simple exposure device was assembled which is based, in effect, on a rotary evaporator (see Figure $\mathrm{x}$ ). The principle is straightforward. The smoke coming from a suitable smoking machine passes through a rotating roundbottom flask. The spinning action keeps a cysteine solution distributed over the inner surface of the flask. The smoke has in this way the opportunity to interact with the liquid film and the cysteine dissolved in it.

Cysteine reacts under these conditions in more than one way: it can be oxidized to cystine, it can combine with aldehydes or activated double bonds thereby forming thiazolidines, hemi-mercaptals, thio-ethers, etc.... (9). In any of these cases the free thiol group disappears. The degree of reaction obtained with smoke

Figure 1. Schematic representation of the exposure device for the determination of the thiol reactivity of cigarette smoke (SH-Index).

A one litre round-bottom flask on a converted rotary evaporator enabling rotation during the passage of smoke, connected to a smoking machine.

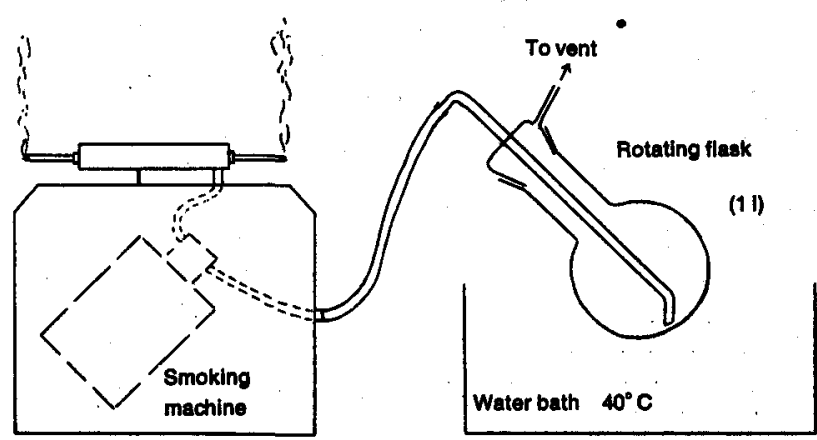


constituents can easily be determined by titrating the remaining unchanged $\mathrm{SH}$ groups. The most convenient way of doing so is by using an automated electrochemical titration apparatus. The reagent preferred is cupric chloride.

\section{METHODOLOGY}

The method requires a smoking machine which produces smoke under standard smoking conditions (8). Our laboratory uses a machine developed by the Battelle Institute, Geneva, which consists in principle of a smoking head for 30 cigarettes that rotates horizontally. A continuously running smoke pump puffs the cigarettes consecutively, achieving in this way a sequence of two-second puffs of consecutive cigarettes. This action results in a quasi-constant smoke stream. The cigarettes are replaced once when the required butt length is reached. The total number of 60 cigarettes, i. e. twice 30 , is thus used for each analysis.

The smoking machine is connected to the exposure device shown in Figure 1. The essential piece of equipment is a one litre round-bottom flask* in which $5 \mathrm{ml}$ of an 0.1 molar cysteine-hydrochloride solution is pipetted prior to smoke exposure.

The smoke of the 60 cigarettes (two machine fills of 30 cigarettes each) is passed through the flask, which is kept rotating on a $40^{\circ} \mathrm{C}$ water bath.

After exposure to the smoke, the solution - which is turbid due to the presence of smoke components - is transferred quantitatively to the titration vessel. In order to ensure that the transfer is quantitative, the flask is rinsed several times with a few millilitres of distilled water. $0.5 \mathrm{ml}$ of 0.5 molar sodium chloride is added to the combined smoke and rinsing solution. This is to ensure a sufficiently high conductivity for the electrometric titration.

The solution is then titrated slowly with 0.1 molar cupric chloride solution. A blank, i. e. a non-exposed cysteine solution, should be titrated to determine the exact consumption for comparison. The titration rate should be slow enough to make the blank determination take about 30 minutes. Faster titration can lead to irreversible side reactions and false results.

The total reaction during titration is:

${ }_{4} \mathrm{CySH}+2 \mathrm{CuCl}_{2} \rightarrow \mathrm{CySSCy}+2 \mathrm{CySCu}+{ }_{4} \mathrm{HCl}$.

The titration curves are evaluated graphically. The results can be expressed in percent cysteine consumption, i. e. corrected cysteine consumption over blank consumption times one hundred. For the sake of convenience, this value was named SH-index in our laboratory.

\footnotetext{
"The volume of one litre was chosen to assure a mean "staying time" of the smoke of one minute. Together with the "dead volume" of the machine the flask volume brings the total space available to the smoke up to around the $1050 \mathrm{ml}$ mark, which corresponds to the amount of smoke produced per minute.
}

\section{Materials}

Number of cigarettes:

60

Solutions:

Cysteine hydrochloride $\quad 0.1 \mathrm{~m}$

Sodium chloride $\quad 0.5 \mathrm{~m}$

Cupric chloride $\quad 0.1 \mathrm{~m}$

\section{Equipment}

Smoking machine for 30 cigarettes

Modified rotary evaporator

Water bath $40^{\circ} \mathrm{C}$

Amperometric titrimeter (preferably with automatic burette and recorder)

Pipettes, titration Hlasks, round-bottom flasks ( 1 l)

\section{Calculation}

$$
\frac{b-x}{b} \times 100=S H-i n d e x \text { (cysteine consumption) }
$$

$\mathrm{b}=$ consumption of $\mathrm{CuCl}_{2}$ in $\mathrm{ml}$ of the blank,

$x=$ consumption of $\mathrm{CuCl}_{2}$ in $\mathrm{ml}$ of the cysteine solution exposed to the smoke of 60 cigarettes.

\section{REPRODUCIBILITY}

Considering the principle of smoke exposure "en passant" it could be suspected that the method is unstable and rather unreliable. Experience has shown, however, that the reproducibility is good and that the errors lie within the range of other smoke-analytical methods. This is illustrated by the example of systematic analyses of two cigarettes which were used in our laboratory to check the method periodically. Both are cigarettes of medium range cysteine consumption, cigarette A with a relatively high delivery of nitric oxide $(260 \mu \mathrm{g} / \mathrm{cigarette})$ and cigarette $B$ with a relatively modest delivery of this compound ( $80 \mu \mathrm{g} / \mathrm{ciga-}$ rette). The results are shown in Table 1.

Table 1. Determination of the thlol reactlvity (SH-index) of two types of clgarette smoke. Mean, standard deviation and coefficient of variation.

\begin{tabular}{l|c|c|c|c}
\cline { 2 - 5 } & $\begin{array}{c}\text { Mean } \\
\text { SH-index }\end{array}$ & $\begin{array}{c}\text { Standard } \\
\text { deviation }\end{array}$ & $\begin{array}{c}\text { Coef- } \\
\text { ficient of } \\
\text { variation }\end{array}$ & $\begin{array}{c}\text { Number } \\
\text { of } \\
\text { analyses }\end{array}$ \\
\hline Cigarette A & 43.1 & 2.5 & $5.9 \%$ & 61 \\
Cigarette B & 36.0 & 1.7 & $4.9 \%$ & 20 \\
\hline
\end{tabular}

\section{REACTIVE SMOKE CONSTITUENTS}

Model experiments have shown that nitric oxide reacts under the described conditions with cysteine. The graph in Figure 2 shows the $\mathrm{SH}$-index as a function of the nitric oxide delivery in smoke. The values 
Figure 2. The SH-Index plotted against the $\mathrm{NO}_{x}$ yield per cigarette (measured as $\mathrm{N}_{2} \mathrm{O}_{2}$ ). The cigarettes for this experiment were made to differ as far as possible mainly in their $\mathrm{NO}_{\mathrm{x}}$ deliveries.

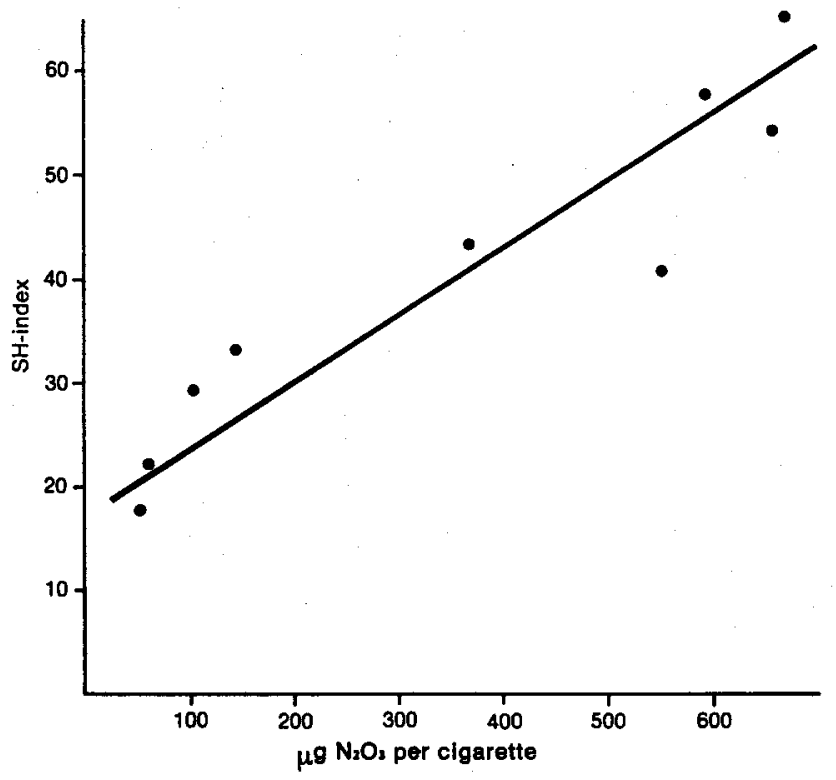

were obtained from cigarettes with increasing nitric oxide deliveries. The yield of other smoke components was kept - as far as possible - constant. The correlation of the data can be seen without difficulty*.

Use of ${ }^{14} \mathrm{C}$ labelled cysteine and thin-layer separation of the reaction products after exposure to smoke, and also after exposure to pure smoke constituents, led to further indications as to reactive compounds.

Although the technique is simple - the thin-layer plates are scanned with a counting device or autoradiographed - the results are rather difficult to elucidate as cysteine tends to interact with already formed cystine causing an exchange of activity, i.e. there is a migration of cysteine entities. This makes it difficult to trace all of the reaction products due to dispersion of amounts of active material. Although it could be shown that formaldehyde, acetaldehyde, acrolein react under the indicated conditions, a large proportion of the $\mathrm{SH}$ reactive in smoke is still unaccounted for.

Work in this direction is continuing. We suspect that the separation methods employed by us are still too slow. This allows newly formed products to undergo further reactions before we are able to identify them. On the other hand, this underlines the usefulness of the titration method because it permits an analytical index to be obtained which is descriptive of a property of truly fresh smoke.

\footnotetext{
* If it is desired to distinguish between how much of cysteine is oxidized to cystine or how much has reacted by alkylating the SH-group, the cystine can be reduced with granulated zinc and the solution can be titrated as usual. In this case only the cysteine consumption induced by "alkylation". is determined. Subtraction of this value from the total consumption - which has to be determined in parallel - leads to the "oxidizing ISH", which is in most tobaccos due to the $\mathrm{NO}_{x}$ in the smoke.

$$
\underset{\text { total }}{\mathrm{ISH}}=\underset{\text { alkylating }}{\text { ISH }}+\underset{\text { oxidizing }}{\text { ISH }}
$$
}

Figure 3. Adsorptlve filtration of smoke: Mlxed adsorbents in the fllfer.

The SH-index of the smoke depends on the filter efficiency. Using the same total quantity (weight) of adsorbents but changing their mixing ratio results in changed smoke composition, which is reflected in different SH-indices.

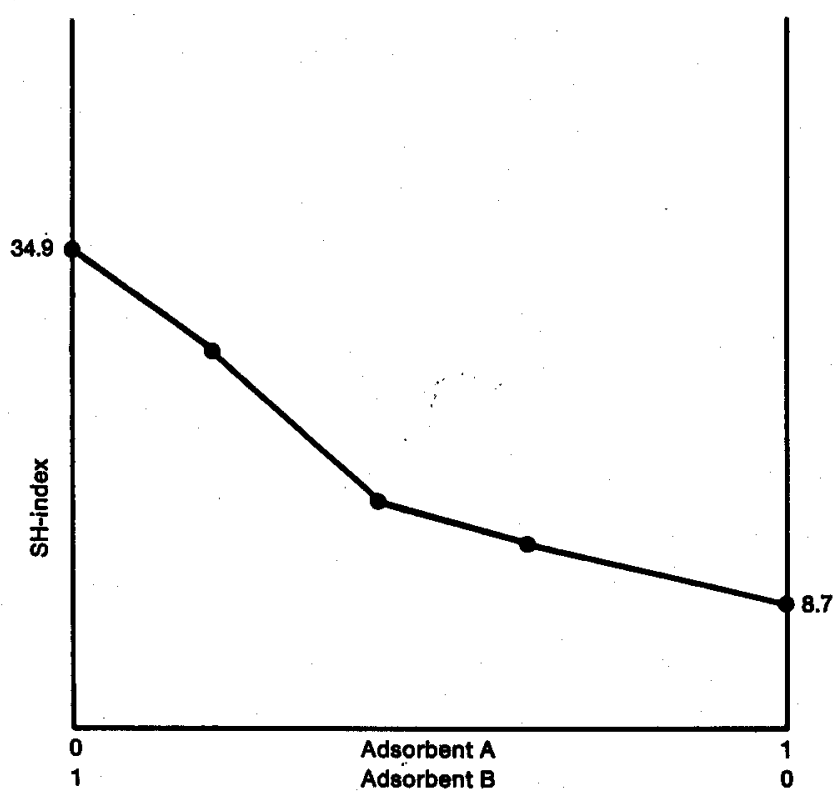

\section{APPLICATION}

The method is used in our laboratory mainly for product screening. A low $\mathrm{SH}$-index indicates to us in less than an hour's work - that a particular cigarette has for example a low $\mathrm{NO}_{x}$ and other gasvapour phase delivery, and that the smoke will probably be judged as mild in subjective terms. It is also used to check the performance of filters and it can give useful information in studies on smoke quality of single tobacco types.

Figure 3 shows how the measurements of the SH-index were used to optimize the mixing ratio of two adsorbents ( $A$ and $B$ ) in a cigarette filter (total quantity $80 \mathrm{mg} / \mathrm{filter}$ ). By increasing the percentage of adsorbent $A$ a sharp drop of the SH-index is achieved initially. At about the 40 percent level a discontinuity occurs and the remaining slope is rather flat. This means that increasing the percentage of adsorbent $A$ beyond that point does not bring much. In other words, by using 40 percent of a highly effective but less specific adsorbent and 60 percent of a more specific but less effective (and less expensive) adsorbent, a good overall filtration can be achieved.

One would perhaps expect the filter performance of two adsorbents blended in variable proportions to be linearly interpolated between the values for the two pure substances. This is, in fact, not the case, as we have seen. There are a number of reasons for this. The totality of interactions between the suspended particulate matter and the gases with the surfaces of adsorbents is very complex and difficult to treat in a 
Table 2. The SH-Index of different tobacco grades.

\begin{tabular}{|c|c|c|c|c|c|c|}
\hline \multirow[b]{2}{*}{ Sample } & \multicolumn{2}{|c|}{ Nicotine } & \multirow[b]{2}{*}{$\begin{array}{l}\text { TPM } \\
\text { (mg/ } \\
\text { ciga- } \\
\text { rette) }\end{array}$} & \multirow[b]{2}{*}{$\begin{array}{c}\mathrm{pH} \\
\text { of the } \\
\text { 2nd } \\
\text { puff }\end{array}$} & \multirow[b]{2}{*}{$\begin{array}{l}\mathrm{pH} \\
\text { of the } \\
\text { last } \\
\text { puff }\end{array}$} & \multirow[b]{2}{*}{$\begin{array}{c}\text { SH- } \\
\text { index }\end{array}$} \\
\hline & $\begin{array}{l}\text { in to- } \\
\text { bacco } \\
\text { (per- } \\
\text { cent) }\end{array}$ & $\mid \begin{array}{c}\text { in smoke } \\
\text { (mg/ } \\
\text { ciga- } \\
\text { rette) }\end{array}$ & & & & \\
\hline Flue-cured 1 & 1.1 & 1.0 & 22.8 & 4.6 & 4.5 & 33.4 \\
\hline Flue-cured 2 & 2.7 & 2.3 & 32.3 & 4.8 & 4.7 & 33.6 \\
\hline Alr-cured 1 & 0.8 & 0.5 & 14.1 & 6.3 & 5.8 & 18.8 \\
\hline Air-cured 2 & 2.3 & 1.7 & 22.1 & 5.5 & 5.5 & 26.5 \\
\hline Air-cured 3 & 0.5 & 0.4 & 14.5 & 6.1 & 6.6 & 31.9 \\
\hline Air-cured 4 & 1.1 & 0.8 & 14.8 & 4.9 & 7.0 & 42.4 \\
\hline Alr-cured 5 & 2.2 & 1.2 & 14.1 & 5.4 & 6.3 & 44.4 \\
\hline Air-cured 6 & 1.5 & 1.0 & 16.5 & 6.7 & 6.7 & 52.2 \\
\hline Alr-cured 7 & 3.2 & 1.7 & 15.9 & 6.1 & 6.5 & 59.6 \\
\hline Air-cured 8 & 2.7 & 1.8 & 21.1 & 6.1 & 8.5 & 64.9 \\
\hline Oriental 1 & 0.7 & 0.8 & 23.1 & 6.3 & 6.5 & 23.0 \\
\hline Oriental 2 & 0.4 & 0.5 & 23.4 & 4.6 & 4.5 & 32.6 \\
\hline
\end{tabular}

theoretical way. This is why the empirical way of proceeding is of high practical importance.

If the same adsorbents A and B are used consecutively, an even more interesting result can be obtained. $40 \mathrm{mg}$ of adsorbent A placed in front of $40 \mathrm{mg}$ of adsorbent $\mathrm{B}$ behaves almost like $80 \mathrm{mg}$ of adsorbent B, i. e. SH-index of nearly 35 . The inverse ordering, namely $B$ in front of $A$, yields almost the same result as pure $\mathrm{A}$, i. e. $\mathrm{SH}$-index near 10 .

Our survey of leaf grades indicates that commercially available tobaccos differ quite substantially in the thiol reactivity of their smoke. The SH-index allows selection among the important groups of tobaccos, e. g. air-cured, bright, etc. ..., of grades that are suitable for a particular cigarette concept. A random selection of results is shown in Table 2 to give an idea of the kinds of values encountered.

Another example to illustrate the usefulness of the method is graphically displayed in Figure 4. A cigarette containing a blend that yields, amongst other things, approximately $200 \mu \mathrm{g}$ of nitric oxide is filtered with increasing quantities of activated carbon. The curve shows clearly that an increase of carbon beyond the $100 \mathrm{mg}$ mark does not result in further decreases of the ISH, and, consequently, is not likely to bring improvements in the "mildness" of the smoke.

The method has an additional attraction. In smoke chemistry the volatiles (vapours) are frequently distinguished from the less volatile particulate matter. In order to study the gas phase, a so-called Cambridge filter is inserted in the smoke stream, which holds back the aerosol droplets and allows the vapours and gases to pass. The insertion of this device results in an arbitrary and incomplete separation, because many volatile compounds such as formaldehyde tend to distribute themselves between the condensed particulate layer and the gas phase $(11,12)$.

The compounds listed earlier which are responsible for the cysteine consumption are fairly volatile. In other words, the method measures practically "gas phase
Figure 4. Increasing quantitles of carbon in a filter reduce the SH-Index In smoke.

Even the use of extreme quantities does not reduce the $\mathrm{SH}$-index below the portion attributable to the presence of $\mathrm{NO}_{\mathbf{x}}$.

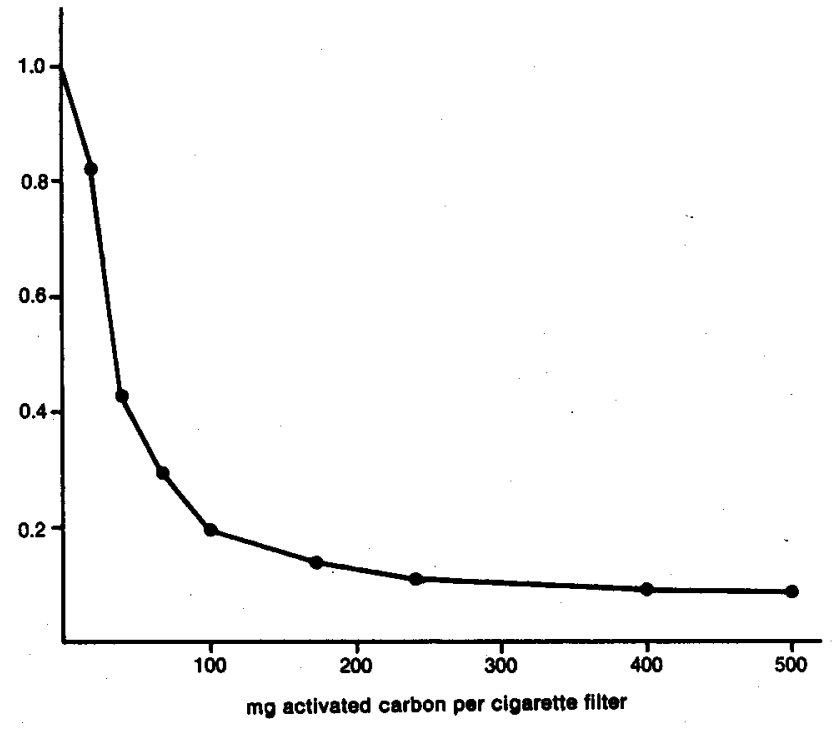

properties" of whole smoke, i. e. smoke that has not been interfered with by the insertion of a Cambridge filter.

We have found in experiments on different types of smoke, using Cambridge filters, that some condensates tend to hold back more SH-reactive compounds on the Cambridge filter than others. In many cases there is little difference between Cambridge filtered smoke and whole smoke. There are also some cases where the Cambridge filtered smoke gives a slightly but significantly increased SH-index. In these cases we think that compounds are desorbed at the Cambridge filter from the condensate which otherwise would not have had time to react in the flask.

Examples of all possibilities have been selected from our results and are indicated in Table 3.

Table 3. The Influence on the SH-Index of Inserting a Cambridge filter in the smoke stream. The group "small decreases" is the most frequently observed. "Sizeable increases". are sometimes measured when low condensate loads are obtained on the Cambridge filter.

\begin{tabular}{l|c|c|c}
\cline { 2 - 4 } & $\begin{array}{c}\text { Total } \\
\text { smoke, no } \\
\text { Cambridge } \\
\text { filter }\end{array}$ & $\begin{array}{c}\text { "Gas- } \\
\text { phase" } \\
\text { Cambridge } \\
\text { filter }\end{array}$ & Remarks \\
\hline Smoke A & 44.2 & 25.2 & Sizeable decrease \\
Smoke B & 62.4 & 60.5 & \\
Smoke C & 55.2 & 50.8 & Small decrease \\
Smoke D & 43.1 & 38.1 & \\
Smoke E & 34.0 & 31.9 & \\
Smoke F & 32.5 & 33.1 & Small increase \\
Smoke G & 25.9 & 28.6 & \\
Smoke H & 14.0 & 17.7 & Sizeable increase \\
Smoke I & 11.5 & 17.2 & \\
\hline
\end{tabular}


An analytical method of establishing a quality index for fresh smoke is described. It is based on the reaction between cysteine and a number of smoke constituents such as oxides of nitrogen, aldehydes and unsaturated carbonyls.

The method can be used for product screening, the measurement of filter performance, or for assessing tobacco quality.

\section{ZUSAMMENFASSUNG}

Es wird eine analytische Methode beschrieben, die es erlaubt, einen Güteindex des Frischraudhes zu bestimmen. Das Prinzip der Methode ist die Reaktion zwischen Cystein und einer Reihe von Rauchbestandteilen wie Stidkoxiden, Aldehyden und ungesättigten Carbonylen.

Die Methode kann für Reihenuntersuchungen an handelsfertigen Cigaretten, zu Messungen der Filterleistung und zur Beurteilung der Tabaksguite herangezogen werden.

\section{RESUME}

On décrit une méthode analytique permettant d'établir un indice de qualité de la fumée frâiche. La méthode est basée sur la réaction entre la cystéine et un certain nombre de composés de la fumée, tels que: oxydes d'azote, aldéhydes et carbonyles insaturés.

La méthode peut être utilisée pour l'évaluation comparative de produits, pour la mesure de l'efficacité du filtre, ou pour juger de la qualité d'un tabac.
1. Driscoll, P., and K. Bättig: Rev. Env. Health 1 (x973) 113-133.

2. Frankenhaeuser, M., A. Myrsten, M. Waszah, A. Neri, and B. Post: Psydhopharmacologica 13 (1968) 311-319.

3. Ashton, H., J. E. Millman, R. Telford, and J. W. Thompson: Brit. J. Pharm. $4^{8}$ (1973) 715-717.

4. Frankenhaeuser, M., A. L. Myrsten, B. Post, and G. Johansson: Psychopharmacologica 22 (1971) $1-7$.

5. Hall, G. H., and C. F. Morrison: Nature 243 (1973) 199-201.

6. Dunn, W. L., Jr.: Smoking behaviour / Motives and incentives; V. H. Winston and Sons, Washington, D. C., 1973.

7. Stauffer, H. P.: Präventivmed. x9 (1974) 55-62.

8. Coresta Standard Method No. 10 (1968): Coresta Information Bulletin 1969-1, 24-33; Coresta Head Office, 53 Quai d'Orsay, Paris-7.

9. Jocelyn, P. C.: Biochemistry of the SH-group; Academic Press, New York and London, 1972.

1o. Testa, A., C. Joigny: Dosage par chromatographie en phase gazeuse (CPG) de l'acroléine et d'autres composés $\alpha, \beta$-insaturés de la phase gazeuse de la fumée de cigarette; Paper No. 86, Coresta/TCRC Joint Conf., Williamsburg, Va., USA, 1972.

xx. Williamson, J. T., and D. R. Allman: Beitr. Tabakforsch. 3 (1966) 590-596.

1.2. Waltz, P., and $M$. Häusermann: Beitr. Tabakforsh. 3 (1965) $169-202$.

The authors' address:

Philip Morris Europe, Research Laboratory, CH-2003 Neuchâtel, Switzerland. 